\title{
Determinants of complications in first ever acute stroke patients: a prospective observational study from India
}

\author{
Vishal Madhukar Sawale ${ }^{1}$, Durjoy Lahiri ${ }^{1}$, Ritwik Ghosh ${ }^{2}$, Souvik Dubey ${ }^{1}$, \\ Gautam Das ${ }^{1}$, Goutam Gangopadhyay ${ }^{1}$, Biman Kanti Ray ${ }^{1, *}$
}

\author{
${ }^{1}$ Bangur Institute of Neurosciences \\ (BIN), Kolkata, West Bengal, India \\ ${ }^{2}$ Burdwan Medical College and Hospital, \\ Burdwan, West Bengal, India
}

\section{*Correspondence}

bimankantiray2019@gmail.com

(Biman Kanti Ray)

\begin{abstract}
Background and Aims: Post-stroke complications can lead to frequent and major causes of death in the early phases after an acute stroke. Aims of the present study were to determine the association of several risk factors with the occurrence of poststroke complications, the predictors for the development of complications, and to evaluate how these complications affected the overall prognosis among subjects with the first ever acute stroke. This study is the pioneer study of this kind from Eastern India. Previous national and international studies on this lack uniformity in their results probably because of the following reasons: no standard definitions for complications following the stroke, varied follow-up periods ranging from 1 week to 30 months, type and severity of stroke affecting the incidence, and finally, the demographic variables.

Methods: This was an observational, prospective study, in which a total of 521 adult male and female patients who had a first-ever acute stroke, aged between 12 years to 75 years were enrolled over a period of 2 years (September 2016 to September 2018), admitted in Department of Neuromedicine, Bangur Institute of Neurosciences (BIN), Kolkata, India. Patients with first ever acute stroke were studied for post-stroke complications (predefined with standard criteria) during the hospital stay at Bangur Institute of Neurosciences (BIN), Kolkata, India, and their association with risk factors, severity of stroke (National Institutes of Health Stroke Scale Score, NIHSS), length of hospital stay (in days) and outcome (Modified Rankin Scale, MRS) were assessed.

Results: A total of screened 498 patients who were admitted at Bangur Institute of Neurosciences (BIN), Kolkata, India, with first ever acute stroke were recruited. The mean age was 61.02 years (range 23-75 years), the majority being male $(n=307 ; 61.6 \%)$. Post-stroke complication during hospital stay was documented in 270 patients $(54.2 \%)$ (males and females combined). In logistic regression analysis, multiple risk factors (OR, $1.571 ; 95 \%$ CI $1.084-2.278 ; P-0.017)$, severity of stroke (National Institutes of Health Stroke Scale Score, NIHSS) (OR, 1.425; 95\% CI, 1.027-1.976; $P-0.034)$ and length of hospital stay (in days) (OR, 3.565; 95\% CI, 2.029-6.264; $P<0.0001$ ) were the most robust predictors of occurrence of complications. The independent predictors of poor outcome in subjects with complications were: chest infection (OR, 2.07; 95\% CI, 1.0064.26; $P=0.048$ ), bedsores (OR, 2.26; 95\% CI, 1.03-4.94; $P-0.042$ ), and seizures (OR, 5.072; 95\% CI, 1.08-23.79; $P-0.039)$.

Conclusion: In our study, the most independent predictors of complications were severity of stroke and length of hospital stay. This observation might help clinicians in taking appropriate measures towards preventing post-stroke complications and thereby improving outcome following a stroke.
\end{abstract}

\section{Keywords}

Post-stroke complications; Length-of-hospital-stay; Post-stroke-outcome; Strokeseverity; Chest-infection

\section{Introduction}

Stroke itself can result in minor to major, short and longterm physical disabilities [1], cognitive impairments [2, 3], emotional disturbances [4, 5], decreased social interactions [6] and excessive economic burden [7]. In addition to neurological problems appearing in the immediate post-stroke period [8], often there are multiple late complications [9] which should 
not to be neglected. These complications have a great impact on one's quality of life after stroke [10], outcomes, and chances of rehabilitation [11].

Stroke is one of the leading causes of disability, financial burden, and mortality worldwide [12-14]. A study revealed higher prevalence of stroke in younger population and high post-stroke short-term mortality in the South Asian region including India, Bangladesh, Sri Lanka and Pakistan [15]. Most of the traditional risk factors for stroke such as diabetes, hypertension, smoking, and heart disease are prevalent in this region [2]. These aforesaid associated co-morbidities hinder post-stroke recovery and increase complications after stroke [16-25]. However, several complications can arise as a direct result of the brain-insult itself, from the ensuing disability or immobility, or even from stroke-related treatments [26]. Stroke-recovery is a multifactorial, dynamic, complex interplay amid genetic, pathobiologic, sociodemographic, and therapeutic factors [26]. These factors have a substantial effect on the final outcome of patients with stroke [26] and if rehabilitation strategies are not optimized and individualized, it will ultimately impede neurological recovery [26]. Johnston KC et al. (1998) demonstrated that post-stroke medical complications have an influence on both mortality and functional outcome [27]. Shah SV et al. (2015) showed that inhospital medical complications following an ischemic stroke or transient ischemic attack are a strong predictor (adjusted HR, 1.68; 95\% CI, 1.04-2.73) of 30-day all-cause readmission [28]. Similar finding was cited by Bae JH et al. [29]. Whereas, Vernino $S$ and colleagues claimed that after the first month of a first ever ischemic stroke, mortality had been higher with cardio-respiratory complications [30]. Early inhospital complications seriously hinder post-stroke outcome in non-fatal strokes as mentioned by Grube MM and colleagues [31]. Cardiac complications, pneumonia, venous thromboembolism, fever; pain, dysphagia, incontinence, and depression are particularly common after stroke [32-35], which usually require specific interventions for their prevention and treatment [32-35]. Moreover, Wang PL et al., Wang P et al., and Kumar $\mathrm{S}$ and colleagues stated in different studies that inhospital medical complications were independently associated with a greater risk of death or dependency in patients with stroke [33-35]. However, wide variations are expected to exist in the complication rates of different studies [32-35] which may be due to the lack of standard definitions for complications following stroke, variable follow-up periods ranging from 1 week to 30 months, and the type and severity of stroke $[26,36]$ affecting the incidence not adjusted for. Finally, some of the variations may be due to the differences in the demographic variables $[26,36]$.

Moreover, there has been a lack of data to establish guidelines for the management of these complications [32, 34]. Systematic investigations are therefore needed further to study the effects of medical complications on stroke recovery and to improve interventions for the prevention and treatment of these events.

\section{Aims and objectives of the study}

This study was conducted primarily to evaluate stroke patients with respect to the development of complications and how that affected their overall prognosis. We studied a relatively large cohort of post-stroke patients for the development of acute complications. We also had tried to determine the associations of several risk factors with the occurrence of complications and tried determining predictors for the development of complications. There have been studies in the past which have studied these aspects. However, wide variations exist in the complication rates of different studies, which may be due to the following reasons: no standard definitions for complications following stroke, varied follow-up periods ranging from 1 week to 30 months, type and severity of stroke affecting the incidence and finally, some of the variations may be due to demographic variables.

Knowledge regarding these parameters is largely lacking in this part of the world and this study is the first of its kind from Eastern India.

\section{Materials and methods}

The study was conducted with prior approval of the institutional ethics committee (IPGME\&R/IEC/2017/294). This is an observational, prospective study, in which a total of 521 adult male and female patients of first-ever stroke, aged between 12 years to 75 years were enrolled over a period of 2 years (September 2016 to September 2018) who were admitted in Department of Neuromedicine, Bangur Institute of Neurosciences (BIN), IPGME\&R, Kolkata, India. Out of these, 498 adult male $(n=307)$ and female $(n=191)$ patients were recruited with informed consent for participation from the patient or patient's relatives, based on the inclusion criteria. All patients attending our centre with first-ever acute stroke excluding who were willing to participate in the study were included. Patients with history of stroke, recurrent stroke, non-acute (old) stroke, age $>75$ years and $<12$ years, and patients with sub-arachnoid hemorrhage $\&$ cortical venous sinus thrombosis were excluded.

The World Health Organization (WHO) defines stroke as: "rapidly developing clinical signs of focal (or global) disturbance of cerebral function, with symptoms lasting 24 hours or longer or leading to death, with no apparent cause other than of vascular origin" [37].

The study included in-hospital medical complications after first-ever acute stroke. The patients were observed daily for any signs of complications until discharge. All complications were checked on a daily basis by the treating neurologists and electronically recorded by stroke team research workers. These complications were defined according to Langhorne $\mathrm{P}$ et al. criterion system [32].

Detailed information on the history of demographic profile of the patient with first ever acute stroke, clinical features (motor deficits, non-motor deficits, and impaired consciousness), risk factors, and type of stroke were noted. Type of stroke was classified as ischemic and hemorrhagic according to the neurio-imaging characteristics. Site of the lesion was broadly categorized as hemispheric cortical and hemispheric 
subcortical. The strokes involving both cortex and subcortex were classified as hemispheric cortical. Severity of stroke was classified using the National Institutes of Health Stroke Scale (NIHSS) as mild (score range: 0-5), moderate (score range: of 6-10), moderately severe (score range: 11-15), or severe (score $>16$ ) [38]. The length of hospital stay was also recorded, and patients were divided into 2 groups according to length of stay ( 7 days and $>7$ days). The days of occurrence of complications were noted.

Subjects were clinically examined by conventional bedside neurological examination methods after detailed history taking. Patients had undergone the following investigations: complete blood count, Biochemical parameters-Urea (mg/dL, Creatinine $(\mathrm{mg} / \mathrm{dL})$, fasting and 2-hour postprandial blood glucose levels $(\mathrm{mg} / \mathrm{dL})$ \& lipid profile $(\mathrm{mg} / \mathrm{dL}), 12$-leadselectrocardiogram (ECG), computed tomography (CT) scan of brain (axial images) and magnetic resonance imaging (MRI) of brain (axial-T1, T2, FLAIR, GRE/SWI, DWI, sagittal-T1, T2, coronal T2, SPGR sequences) when required.

Functional outcome was assessed using the modified Rankin scale (mrs) at the time of discharge (table given below). Good outcome (mrs score 0-2) was defined as survival with no or minimal neurologic deficits and functional independence. Poor outcome (mrs score: 3-6) was defined as survival with significant neurologic deficits/functional dependence requiring institutional care or death directly related to the stroke or its complications.

All statistical analyses were done using SPSS 16.0 (SPSS Inc., Chicago, IL, USA). The Chi square and Fisher's exact tests were done to study the factors associated with and without complications. The means of continuous variables were compared using the Student $t$-test. Univariate analysis included the following factors: age, sex, clinical features, type of stroke, risk factors for stroke, length of hospital stay ( $>$ 7 days or 7 days), stroke severity based on NIHSS (mild to moderate: NIHSS 0-10; moderately severe to severe: NIHSS $>11)$ and the functional outcome of stroke based on Modified Rankin Scale (mrs) (good: mrs score 0-2; poor: mrs score 3-6). Multivariate binary logistic regression analysis was done to explore the factors associated with complications after adjusting for confounding factors, such as age, sex, and risk factors for stroke. In addition, multivariate logistic regression was performed to explore the association between individual complications and outcome. A $P$ value of $<0.05$ was considered significant.

\section{Results and analysis}

In our study, the mean age of the patients was found to be 61.02 years $(\mathrm{SD}=9.69)$. Majority $(74.9 \%, \mathrm{n}=373)$ patients were aged 50 years or more, of which $56.30 \%(n=210)$ developed at least one complication during hospital stay (Table 1: Characteristics of Patients). Majority were males $(n=307$, $61.65 \%$ ). The most common risk factor noted in our study was hypertension $(\mathrm{n}=247,49.60 \%)$, followed by diabetes $(\mathrm{n}$ $=133,26.70 \%)$ and smoking $(\mathrm{n}=122,24.50 \%)$. Other factors which contributed to potential risk were CAD $(16.90 \%, \mathrm{n}=$ $84)$, dyslipidemia $(18.70 \%, \mathrm{n}=93)$, hypothyroidism $(8.40 \%, \mathrm{n}$ $=42)$, alcohol $(9.80 \%, \mathrm{n}=49)$, AF $(6.80 \%, \mathrm{n}=34)$, and RHD
$(1 \%, \mathrm{n}=5)$. Multiple risk factors (at least two) were present in $49.60 \%(n=247)$ of the patients suffering from the first ever acute stroke, whereas a single risk factor was present in $50.4 \%$ $(\mathrm{n}=251)$ of our study population.

In our study, $86.90 \%(n=433)$ of the patients were admitted within 72 hours after the occurrence of the first ever acute stroke, while only $13.10 \%(n=65)$ of the patients were admitted after 72 hours (Table 2: Characteristics of Stroke). Regarding presenting clinical features, the majority of the patients, i.e. $65.3 \%(\mathrm{n}=325)$, developed motor deficits (hemiparesis, dysarthria, ataxia, seizure, dysphagia) after stroke; $21.7 \%$ (n $=108$ ) of the patients developed non motor deficits (headache, hemisensory loss, vertigo, aphasia, social inhibition, vomiting, neglect and hemi-anopia); and $13.5 \%(n=67)$ of the patients presented with impaired consciousness. Majority of the study population $63.1 \%(\mathrm{n}=314)$ suffered from ischemic stroke and the rest $36.9 \%(\mathrm{n}=184)$ suffered from hemorrhagic stroke. The majority of the patients $(70.1 \% ; n=349)$ developed stroke due to lesions in the hemispheric subcortex, while $29.9 \%$ (n $=149$ ) of them developed lesions in the hemispheric cortex. A total of $66.9 \%(n=333)$ patients developed moderate to severe stroke (NIHSS $>/=11)$, while $33.1 \%(n=165)$ of the patients developed mild to moderate strokes (NIHSS $<11$ ). The majority of the post stroke patients $(75.1 \%, \mathrm{n}=374)$ had a shorter length of stay of 7 days and $24.9 \%(n=124)$ of the patients had a prolonged length of stay in the hospital $(>7$ days). A total of $69.7 \%(n=347)$ of the post-stroke patients had good outcome at the time of discharge (mrs $0-2)$ and $30.3 \%$ $(\mathrm{n}=151)$ of the total number of patients had poor outcome (mrs 3-6) at the time of discharge.

Out of 498 patients with first ever acute stroke, 270 (54.2\%) developed at least one complication (Table 3: Complications in stroke patients). The most frequent complication was infections accounting for $34.2 \%(n=170)$ of the total study population. Among infections, UTI was the most common (n $=73 ; 14.7 \%)$, followed by Chest infection $(\mathrm{n}=72 ; 14.5 \%)$. Other infections (Any febrile illness lasting for $>24$ hours) were found in $5 \%(\mathrm{n}=25)$.

Various factors were associated with complications on univariate analysis as shown in Table 1 . These significant factors $(P<0.05)$ were hypertension $(P-0.011)$, diabetes $(P-$ $0.027)$, smoking $(P-0.004)$, time of admission $>72$ hours $(P$ $0.009)$, Ischemic stroke $(P-0.01)$, hemispheric cortical strokes $(P<0.0001)$, motor deficit $(P-0.009)$, non motor deficit $(P<$ $0.0001)$, impaired consciousness $(P-0.011)$, NIHSS and length of stay more than 7 days.

In logistic regression analysis (Table 4 ), multiple risk factors (2) (OR, 1.571; 95\% CI, 1.084-2.278; $P$-0.017), stroke severity (NIHSS Score) (OR, 1.425; 95\% CI, 1.027-1.976; $P-0.034)$ and length of hospital stay (OR, 3.565; 95\% CI, 2.029-6.264; $P<0.0001)$ were the most robust predictors of occurrence of complications.

The independent predictors of poor outcome (Table 5) in subjects with complications were chest infection (OR, 2.07; 95\% CI, 1.006-4.26; $P=0.048$ ), bedsores (OR, 2.26; 95\% CI, $1.03-4.94 ; P=0.042)$, and seizure (OR, 5.072; 95\% CI, 1.0823.79; $P=0.039$ ). 
TA B LE 1. Characteristics of Patients.

\begin{tabular}{|c|c|c|c|c|}
\hline PATIENT CHARAC & TERISTICS & WITH COMPLICATIONS (\%) & WITHOUT COMPLICATIONS (\%) & $P$ VALUE \\
\hline AGE & $>50$ & $56.30 \%$ & $43.70 \%$ & 0.107 \\
\hline (YEARS) & $<50$ & $48.0 \%$ & $52.0 \%$ & 0.107 \\
\hline SFY & MALE & $56.67 \%$ & $43.33 \%$ & 0162 \\
\hline $\mathrm{SL} \boldsymbol{\Lambda}$ & FEMALE & $50.26 \%$ & $49.74 \%$ & 0.102 \\
\hline RISK FACTORS & & & & \\
\hline HYPFRTFNSION & Present & $59.9 \%$ & $40.1 \%$ & $0011 *$ \\
\hline 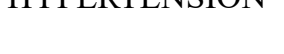 & Absent & $48.6 \%$ & $51.4 \%$ & 0.011 \\
\hline DIARFTES & Present & $62.4 \%$ & $37.6 \%$ & $0027^{*}$ \\
\hline & Absent & $51.2 \%$ & $48.8 \%$ & \\
\hline SMOKING & Present & $65.6 \%$ & $35.4 \%$ & $0004 *$ \\
\hline SIVIUNINU & Absent & $50.5 \%$ & $49.5 \%$ & 0.004 \\
\hline AI COHOI & Present & $42.9 \%$ & $57.1 \%$ & 0093 \\
\hline ALCUHUL & Absent & $55.5 \%$ & $44.5 \%$ & 0.093 \\
\hline CAD & Present & $58.3 \%$ & $41.7 \%$ & 0406 \\
\hline CAD & Absent & $53.4 \%$ & $46.6 \%$ & 0.406 \\
\hline$\Delta \mathrm{F}$ & Present & $61.8 \%$ & $38.2 \%$ & 0360 \\
\hline AF & Absent & $53.7 \%$ & $46.3 \%$ & 0.360 \\
\hline & Present & $42.9 \%$ & $57.1 \%$ & 0123 \\
\hline HYPOTHYROID & Absent & $55.3 \%$ & $44.7 \%$ & 0.123 \\
\hline DYSI JPIDFMIA & Present & $46.2 \%$ & $53.8 \%$ & 0087 \\
\hline D I SEII IDENITH & Absent & $56.0 \%$ & $44.0 \%$ & 0.00 \\
\hline
\end{tabular}

The mean age of the patients was found to be 61.02 years $(S D=9.69)$. Majority $(74.9 \%, n=373)$ patients were aged $\geq 50$ years, of which $56.30 \%(n=210)$ developed $\geq 1$ complication during hospital stay. Majority were males $(n=307,61.65 \%)$. The most common risk factor noted in our study was hypertension ( $n=247,49.60 \%)$, followed by diabetes $(n=133,26.70 \%)$ and smoking $(n=122,24.50 \%)$. Multiple risk factors $(\geq 2)$ were present in $49.60 \%$ $(n=247)$ of the patients suffering from first ever acute stroke.

\section{Discussion}

This study was carried out with the aim of studying the occurrence of complications in patients presenting with a first ever episode of acute stroke, determining factors predicting the development of such complications and how they affect the functional outcome of these patients.

A total of 498 screened patients out of 521 patients were recruited for our study. The most noteworthy observation in our study was that more than half of the study population developed at least one complication during their hospital stay, comparable to the frequency of complications reported in previous studies by Langhorne $\mathrm{P}$ et al. (complications in $85 \%$ of patients [32], Ingeman A et al. in 25.2\% [39], Roth EJ et al. in 75\% [40], Kitisomprayoonkul W et al. in 70.3\% [41], Hung JW et al. in 44\% [42], and Kalra L and colleagues in 60\% [43].

More than half of the patients who developed complications were above the age of 50 years. This is in keeping with a study published by Doshi VS et al. [44], which also found an increasing rate of complications with increasing age. Another study by Knoflach $\mathrm{M}$ et al. [45] also showed poor functional outcome in stroke patients with a higher age. This may be ascribed to the established fact that the elderly population bears the major portion of the burden of co-morbid ailments.

Compared to females, a greater percentage of males were found to have complications in this study. A study by Colbert JF et al. [46] showed that females are less likely to develop post-stroke complications like pneumonia and sepsis. However, there are two studies that show an increased rate of complications among female patients [44, 47], especially an increased rate of certain complications like UTI and depression among females [44]. This gender discrepancy may be ascribed to poor healthcare delivery to women particularly the elderly women in rural India and the prevailing gender discrimination [48-51].

The most common complication noted in almost one-third of the study population was infection followed closely by pain and problems arising out of immobility like pressure sore, falls, and pulmonary embolism. Amidst infectious processes, urinary tract and chest infections were seen almost equally to be the predominant sources of sepsis. The other common complications noted were depression, coronary artery disease, cardiac conduction defects, and gastro-intestinal hemorrhage. Development of respiratory tract infection was also associated with a poor functional outcome, whereas seizures and bedsores are the other two worth mentioning predictors of poor 
TA B L E 2. Characteristics of Stroke.

\begin{tabular}{|c|c|c|c|c|}
\hline STROKE CHARACTERISTICS & & $\begin{array}{c}\text { WITH } \\
\text { COMPLICATIONS (\%) }\end{array}$ & $\begin{array}{c}\text { WITHOUT } \\
\text { COMPLICATIONS (\%) }\end{array}$ & $P$ VALUE \\
\hline \multicolumn{5}{|l|}{ TIME OF ADMISSION } \\
\hline$>72$ HOURS & & $69.20 \%$ & $30.80 \%$ & $0.009^{*}$ \\
\hline$<72$ HOURS & & $52.00 \%$ & $48.00 \%$ & \\
\hline \multicolumn{5}{|l|}{ CLINICAL FEATURES } \\
\hline \multirow[t]{2}{*}{ MOTOR DEFICIT } & Present & $58.50 \%$ & $41.50 \%$ & $0.009^{*}$ \\
\hline & Absent & $46.2 \%$ & $53.8 \%$ & \\
\hline \multirow[t]{2}{*}{ NON MOTOR DEFICIT } & Present & $33.30 \%$ & $66.70 \%$ & $<0.0001^{*}$ \\
\hline & Absent & $60.0 \%$ & $40.0 \%$ & \\
\hline \multirow[t]{2}{*}{ IMPAIRED CONSCIOUSNESS } & Present & $68.70 \%$ & $31.30 \%$ & $0.011^{*}$ \\
\hline & Absent & $52.0 \%$ & $48.0 \%$ & \\
\hline \multicolumn{5}{|l|}{ TYPE OF STROKE } \\
\hline ISCHAEMIC & & $58.60 \%$ & $41.40 \%$ & $0.010^{*}$ \\
\hline HAEMORRHAGIC & & $46.70 \%$ & $53.30 \%$ & \\
\hline \multicolumn{5}{|l|}{ SITE OF LESION } \\
\hline HEMISPHERIC CORTICAL & & $68.50 \%$ & $31.50 \%$ & \\
\hline HEMISPHERIC & & $48.10 \%$ & $51.90 \%$ & $<0.0001^{*}$ \\
\hline \multicolumn{5}{|l|}{ SUBCORTICAL } \\
\hline \multicolumn{5}{|l|}{ NIHSS } \\
\hline & & $71.80 \%$ & $28.20 \%$ & $<0.0001^{*}$ \\
\hline 11 & & $18.80 \%$ & $81.20 \%$ & \\
\hline \multicolumn{5}{|l|}{ LENGTH OF STAY } \\
\hline 7 DAYS & & $86.30 \%$ & $13.70 \%$ & $<0.0001^{*}$ \\
\hline 7 DAYS & & $43.60 \%$ & $56.40 \%$ & \\
\hline \multicolumn{5}{|l|}{ FUNCTIONAL OUTCOME (mrs) } \\
\hline POOR OUTCOME (mrs 3-6) & & $80.80 \%$ & $19.20 \%$ & $<0.0001^{*}$ \\
\hline GOOD OUTCOME (mrs 0-2) & & $42.70 \%$ & $57.30 \%$ & \\
\hline
\end{tabular}

In this study, $86.90 \%(n=433)$ of the patients were admitted within 72 hours after occurrence of first ever acute stroke. $65.3 \%(n=325)$ developed post stroke motor deficits, $21.7 \%(n=108)$ developed non-motor deficits and $13.5 \%(n=$ 67) presented with impaired consciousness. $63.1 \%(n=314)$ suffered from ischemic stroke and the rest $36.9 \%(n=$ 184) had hemorrhagic stroke. $70.1 \%(n=349)$ developed stroke due to lesions in the hemispheric subcortex, while $29.9 \%(n=149)$ developed lesions in the hemispheric cortex. A total of $66.9 \%(n=333)$ patients had NIHSS 11 , while $33.1 \%(n=165)$ had NIHSS $<11.24 .9 \%(n=124)$ had prolonged length of stay in the hospital $(>7$ days $)$. A total of $69.7 \%(n=347)$ had good outcome at the time of discharge (mrs $0-2)$ and $30.3 \%(n=151)$ had poor outcome (mrs 3-6) at the time of discharge.

prognosis. Most studies have published results similar to our findings [52-55]. A multi-center Indian study published by Pandian JD et al. [56], concluded with similar results with chest and urinary tract infections being the most common sources of infection among stroke patients, which also resulted in a poor outcome. Westendorp et al. [57] also found such infections to be the most common complication in their study and pneumonia was the most important cause of death in their patients. Such findings are probably because a large number of patients are catheterized for a considerable length of time in post stroke period, which serve as an important source of urinary tract infection in these patients. Most patients, owing to immobility, showed decreased consciousness levels, and poor reflexes, and aspirated food particles or oral secretions leading to respiratory tract infections.

In our study, hypertension was the most common risk factor, followed by diabetes and smoking. Patients with ischemic stroke were found to have higher chances of developing poststroke complications, and most of these complications occurred within the first week after acute stroke. We used the most widely used and validated stroke scale-National Institutes of Health Stroke Scale (NIHSS) [38], to accurately establish stroke severity and prognosis in our patients. It was seen that patients with moderate to severe stroke (NIHSS score $\geq 11$ ) had more complications than those with milder stroke (NIHSS score $<11$ ), thus portending a poorer outcome. Most studies 
TA B L E 3. Complications in stroke patients.

\begin{tabular}{|c|c|c|c|}
\hline \multicolumn{2}{|c|}{ COMPLICATIONS } & \multirow{2}{*}{ NUMBER (N) } & \multirow{2}{*}{$\begin{array}{c}\text { PERCENT (\%) } \\
14.5\end{array}$} \\
\hline \multirow{3}{*}{ Infections } & Chest Infection & & \\
\hline & UTI & 73 & 14.7 \\
\hline & Other Infection & 25 & 5 \\
\hline \multirow{3}{*}{ Neurological } & Seizure & 31 & 6.2 \\
\hline & Recurrent Stroke & 10 & 2 \\
\hline & Bedsore & 58 & 11.6 \\
\hline \multirow{3}{*}{ Immobility } & Falls & 5 & 1 \\
\hline & DVT & 10 & 2 \\
\hline & Pulmonary Embolism & 5 & 1 \\
\hline \multirow{2}{*}{ Pain } & Shoulder Pain & 68 & 13.7 \\
\hline & Other Pain (Neck pain, LBP, joint pain other than shoulder and others) & 70 & 14.1 (cumulative) \\
\hline \multirow{2}{*}{ Psychological } & Depression & 69 & 13.9 \\
\hline & Other psychological (confusion, anxiety, emotionalism) & 47 & 9.44 (cumulative) \\
\hline Miscellaneous & $\begin{array}{l}\text { AMI, cardiac arrhythmias, GI haemorrhage and dysfunctional uterine } \\
\text { bleeding. }\end{array}$ & 14 & 2.8 \\
\hline
\end{tabular}

Out of 498 patients of first ever acute stroke 270 (54.2\%) developed $\geq 1$ complication. The most frequent complication was infections $(34.2 \%(n=170))$; among which, UTI was the most common $(n=73 ; 14.7 \%)$ followed by chest infection $(n=72$; $14.5 \%)$.

TA B L E 4. Predictors of complications by multivariate logistic regression analysis.

\begin{tabular}{lccccc} 
PREDICTORS OF COMPLICATIONS & $P$ Value & OR & \multicolumn{2}{c}{$95 \%$ CI } \\
& & & Lower & Upper \\
1. MULTIPLE RISK FACTORS (2) & 0.017 & 1.571 & 1.084 & 2.278 \\
2. NIHSS & 0.034 & 1.425 & 1.027 & 1.976 \\
3. Length of Hospital Stay (days) & 0.000 & 3.565 & 2.029 & 6.264 \\
\hline In logistic regression analysis, multiple risk factors (2) (OR, $1.571 ; 95 \%$ \\
CI, 1.084-2.278; P-O.017), severity of stroke (NIHS Score) (OR, 1.425; $95 \%$ \\
CI, 1.027-1.976; P-0.034) and length of hospital stay (OR, 3.565; 95\% CI, \\
2.029-6.264; P $<0.0001)$ were the most robust predictors of occurrence of \\
complications.
\end{tabular}

TA B L E 5. Predictors of poor outcome by multivariate logistic regression analysis.

\begin{tabular}{lcccc} 
PREDICTORS OF POOR OUTCOME & $P$ Value & OR & \multicolumn{2}{c}{$95 \%$ CI } \\
& & & Lower & Upper \\
1. CHEST INFECTION & 0.048 & 2.070 & 1.006 & 4.260 \\
2. SEIZURE & 0.039 & 5.072 & 1.081 & 23.793 \\
3. BEDSORE & 0.042 & 2.255 & 1.029 & 4.940
\end{tabular}

The independent predictors of poor outcome in subjects with complications were chest infection (OR, 2.07; 95\% CI, 1.006-4.26; P-0.048), bedsores (OR, 2.26; 95\% CI, 1.034.94; P-0.042), and seizure (OR, 5.072; 95\% CI, 1.08-23.79; P-0.039).

have established NIHSS score as a good predictor of outcome and prognosis of stroke [58-60]. A study by Haeusler et al. [61] showed that a higher NIHSS score was the best predictor of development of infections in patients with stroke. Pandian JD et al. [56] in 2012 and a study by Roth EJ et al. [25] also showed similar results.

We also attempted to find how the length of hospital stay affected the development of complications and outcomes in stroke patients. In our study, the majority of the patients had a shorter length of stay of 7 days and only one-third patients had a longer length of stay in the hospital ( $>7$ days). We found that those who had a longer length of stay developed at least one complication during their stay. Interpretation of observational data on complications and length of stay is 
a challenge as pointed out in earlier studies, where medical complications were also associated with longer length of stay among patients with acute stroke [62, 63]. Previous studies by Tong X et al., Spratt N et al., Tirschwell DL et al., found that infections particularly were associated with longer length of stay [64-69]. It is therefore difficult to determine whether a longer length of stay is caused by medical complications or whether a longer length of stay itself was a cause of these complications. Langhorne $\mathrm{P}$ et al. [32] found that most of the medical complications developed early after hospital admission, which might support the hypothesis that medical complications per se may increase the length of stay. In this study, the majority of patients who suffered from at least one complication during their hospital stay were associated with poor outcome (mrs 3-6) at the time of discharge.

The presence of multiple risk factors was found to be the other important predictor of the occurrence of complications and functional outcome as assessed by multivariate logistic regression analysis. There are several studies which have shown that the presence of risk factors like hypertension, diabetes, smoking, and even aging all portend a poorer prognosis in stroke [16-25, 70-74]. Most of our patients had multiple risk factors, suggesting that the presence of more than one risk factor worsens prognosis in stroke.

\section{Limitations of the study}

However, this study had a few limitations. The complications were noted only during the hospital stay, and they were not categorized according to severity. Besides, for a study on assessment of post-stroke cognitive impairment, at least three months of post-stroke follow-up would have been required, which is however beyond the scope of this study. Hence, comments on post-stroke cognition were not discussed in this particular study. Undoubtedly, a long-term study with followup would give a more clear idea regarding the development of late complications and a picture of the resultant morbidity.

\section{Conclusions}

In this study, the most independent predictors of after-stroke complications were; 1) presence of multiple risk factors, 2) severity of stroke, and 3) length of hospital stay. Predictors of poor outcome were noted to be 1) chest infection, 2) pressure sore, and 3 ) seizures. These observations might help clinicians in taking appropriate measures towards preventing post-stroke complications and thereby improving post-stroke outcome. Further studies to evaluate long term complications and outcomes are required to formulate definite guidelines regarding the prophylaxis and secondary prevention of complications in patients with stroke.

\section{ETHICS APPROVAL AND CONSENT TO PARTICIPATE}

The study was conducted with prior approval of the institutional ethics committee (IPGME\&R/IEC/2017/294).

\section{AUTHOR CONTRIBUTIONS}

VMS, DL, and RG were involved in study planning, data extraction, and primary draft writing; DL, SD and RG were involved in data extraction, analysis, and primary draft writing; GD and GG also participated in data extraction, data analysis, and primary draft writing; BKR was sincerely involved in data extraction, data analysis, and primary draft writing; RG, DL, $\mathrm{SD}, \mathrm{GD}, \mathrm{GG}, \mathrm{BKR}$ critically revised the whole draft and all the authors agreed to the final form of the manuscript.

\section{ACKNOWLEDGMENT}

The authors thank the entire faculty members of team BIN (Bangur Institute of Neurosciences) for help with the preparation of this manuscript. The authors acknowledge the institutional support from IPGMER and SSKM Hospital. Thank numerous individuals (patients) who consented for participation in this study. We would also like to express my gratitude to all those who helped me during the writing of this manuscript. And last but not the least many thanks to all the peer reviewers for their opinions and suggestions. We express our gratitude for Professor Dr. Pedro J. Modrego. (Department of Neurology, Hospital Miguel Servet, Zaragoza, Spain; pmpjmp@gmail.com) for his endless inspiration, constant support and vision.

\section{FUNDING}

The Bangur Institute of Neurosciences (BIN) funded all the investigations without any other grant, aid or sponsorship from any other authority.

\section{CONFLICT OF INTEREST}

The authors have no conflicts of interest to declare.

\section{REFERENCES}

[1] Charfi N, Trabelsi S, Turki M, Mâalej Bouali M, Zouari L, Dammak M, et al. Impact du handicap physique et des troubles émotionnels concomitants sur la qualité de vie en post-AVC. L'EncéPhale. 2017; 43: 429-434. (In French)

[2] Mijajlović MD, Pavlović A, Brainin M, Heiss W, Quinn TJ, Ihle-Hansen $\mathrm{HB}$, et al. Post-stroke dementia-a comprehensive review. BMC Medicine. 2017; 15: 11 .

[3] Brainin M, Tuomilehto J, Heiss W, Bornstein NM, Bath PMW, Teuschl Y, et al. Post-stroke cognitive decline: an update and perspectives for clinical research. European Journal of Neurology. 2015; 22: 229-238, e13-6.

[4] Doruk D, Simis M, Imamura M, Brunoni AR, Morales-Quezada L, Anghinah R, et al. Neurophysiologic correlates of post-stroke mood and emotional control. Frontiers in Human Neuroscience. 2016; 10: 428.

[5] McAleese N, Guzman A, O'Rourke SJ, Gillespie DC. Post-stroke emotionalism: a qualitative investigation. Disability and Rehabilitation. 2019; 65: $1-9$.

[6] Lehnerer S, Hotter B, Padberg I, Knispel P, Remstedt D, Liebenau A, et al. Social work support and unmet social needs in life after stroke: a cross-sectional exploratory study. BMC Neurology. 2019; 19: 220.

[7] Rajsic S, Gothe H, Borba HH, Sroczynski G, Vujicic J, Toell T, et al. Economic burden of stroke: a systematic review on post-stroke care. The European Journal of Health Economics. 2019; 20: 107-134.

[8] Bovim MR, Askim T, Lydersen S, Fjærtoft H, Indredavik B. Com- 
plications in the first week after stroke: a 10-year comparison. BMC Neurology. 2016; 16: 133.

[9] Chohan S, Venkatesh P, How C. Long-term complications of stroke and secondary prevention: an overview for primary care physicians. Singapore Medical Journal. 2019; 60: 616-620.

[10] Khalid W, Rozi S, Ali TS, Azam I, Mullen MT, Illyas S, et al. Quality of life after stroke in Pakistan. BMC Neurology. 2016; 16: 250.

[11] Lui SK, Nguyen MH. Elderly stroke rehabilitation: overcoming the complications and its associated challenges. Current Gerontology and Geriatrics Research. 2018; 2018: 9853837.

[12] GBD 2016 Stroke Collaborators. Global, regional, and national burden of stroke, 1990-2016: a systematic analysis for the Global Burden of Disease Study 2016. The Lancet Neurology. 2019; 18: 439-458.

[13] Krishnamurthi RV, Feigin VL, Forouzanfar MH, Mensah GA, Connor M, Bennett DA, et al. Global and regional burden of first-ever ischaemic and haemorrhagic stroke during 1990-2010: findings from the Global Burden of Disease Study 2010. The Lancet Global Health. 2013; 1: e259-e281.

[14] Virani SS, Alonso A, Benjamin EJ, Bittencourt MS, Callaway CW, Carson AP, et al. Heart disease and stroke statistics-2020 update: a report from the American Heart Association. Circulation. 2020; 141: e139e596.

[15] Wasay M, Khatri IA, Kaul S. Stroke in South Asian countries. Nature Reviews Neurology. 2014; 10: 135-143.

[16] Lau L, Lew J, Borschmann K, Thijs V, Ekinci EI. Prevalence of diabetes and its effects on stroke outcomes: a meta-analysis and literature review. Journal of Diabetes Investigation. 2019; 10: 780-792.

[17] Huynh W, Kwai N, Arnold R, Krishnan AV, Lin CS, Vucic S, et al. The effect of diabetes on cortical function in stroke: implications for poststroke plasticity. Diabetes. 2017; 66: 1661-1670.

[18] Sweetnam D, Holmes A, Tennant KA, Zamani A, Walle M, Jones P, et al. Diabetes impairs cortical plasticity and functional recovery following ischemic stroke. Journal of Neuroscience. 2012; 32: 5132-5143.

[19] Maïer B, Kubis N. Hypertension and its impact on stroke recovery: from a vascular to a parenchymal overview. Neural Plasticity. 2019; 2019: 1-14.

[20] Bager J, Hjalmarsson C, Manhem K, Andersson B. Acute blood pressure levels and long-term outcome in ischemic stroke. Brain and Behavior. 2018; 8: e00992.

[21] Matsuo R, Ago T, Kiyuna F, Sato N, Nakamura K, Kuroda J, et al. Smoking status and functional outcomes after acute ischemic stroke. Stroke. 2020; 51: 846-852.

[22] Kumagai N, Okuhara Y, Iiyama T, Fujimoto Y, Takekawa H, Origasa H, et al. Effects of smoking on outcomes after acute atherothrombotic stroke in Japanese men. Journal of the Neurological Sciences. 2013; 335: 164-168.

[23] Cuadrado-Godia E, Ois A, Roquer J. Heart failure in acute ischemic stroke. Current Cardiology Reviews. 2010; 6: 202-213.

[24] Battaglini D, Robba C, Lopes da Silva A, dos Santos Samary C, Leme Silva P, Dal Pizzol F, et al. Brain-heart interaction after acute ischemic stroke. Critical Care. 2020; 24: 163.

[25] Roth EJ. Heart disease in patients with stroke. Part II: impact and implications for rehabilitation. Archives of Physical Medicine and Rehabilitation. 1994; 75: 94-101.

[26] Alawieh A, Zhao J, Feng W. Factors affecting post-stroke motor recovery: implications on neurotherapy after brain injury. Behavioural Brain Research. 2018; 340: 94-101.

[27] Johnston KC, Li JY, Lyden PD, Hanson SK, Feasby TE, Adams RJ, et al. Medical and neurological complications of ischemic stroke. Stroke. 1998; 29: 447-453.

[28] Shah SV, Corado C, Bergman D, Curran Y, Bernstein RA, Naidech AM, et al. Impact of poststroke medical complications on 30-day readmission rate. Journal of Stroke and Cerebrovascular Diseases. 2015; 24: 19691977.

[29] Bae H, Yoon D, Lee J, Kim B, Koo J, Kwon O, et al. In-hospital medical complications and long-term mortality after ischemic stroke. Stroke. 2005; 36: 2441-2445.

[30] Vernino S, Brown RD, Sejvar JJ, Sicks JD, Petty GW, O'Fallon WM. Cause-specific mortality after first cerebral infarction. Stroke. 2003; 34: 1828-1832.

[31] Grube MM, Koennecke H, Walter G, Meisel A, Sobesky J, Nolte CH, et al. Influence of acute complications on outcome 3 months after ischemic stroke. PLoS ONE. 2013; 8: e75719.
[32] Langhorne P, Stott DJ, Robertson L, MacDonald J, Jones L, McAlpine C, et al. Medical complications after stroke. Stroke. 2000; 31: 1223-1229.

[33] Wang P, Zhao X, Yang Z, Wang A, Wang C, Liu L, et al. Effect of in-hospital medical complications on case fatality post-acute ischemic stroke: data from the China National Stroke Registry. Chinese Medical Journal. 2013; 125: 2449-2454.

[34] Kumar S, Selim MH, Caplan LR. Medical complications after stroke. The Lancet Neurology. 2010; 9: 105-118.

[35] Wang P, Wang Y, Zhao X, Du W, Wang A, Liu G, et al. In-hospital medical complications associated with stroke recurrence after initial ischemic stroke. Medicine. 2016; 95: e4929.

[36] Kim B, Lee J, Sohn MK, Kim DY, Lee S, Shin Y, et al. Risk factors and functional impact of medical complications in stroke. Annals of Rehabilitation Medicine. 2017; 41: 753-760.

[37] Warlow C. Epidemiology of stroke. The Lancet. 1998; 352: S1-S4.

[38] Kwah LK, Diong J. National Institutes of Health Stroke Scale (NIHSS). Journal of Physiotherapy. 2014; 60: 61.

[39] Ingeman A, Andersen G, Hundborg HH, Svendsen ML, Johnsen SP. In-hospital medical complications, length of stay, and mortality among stroke unit patients. Stroke. 2011; 42: 3214-3218.

[40] Roth EJ, Lovell L, Harvey RL, Heinemann AW, Semik P, Diaz S. Incidence of and risk factors for medical complications during stroke rehabilitation. Stroke. 2001; 32: 523-529.

[41] Kitisomprayoonkul W, Sungkapo P, Taveemanoon S, Chaiwanichsiri D. Medical complications during inpatient stroke rehabilitation in Thailand: a prospective study. Journal of the Medical Association of Thailand. 2010; 93: 594-600.

[42] Hung J, Tsay T, Chang H, Leong C, Lau Y. Incidence and risk factors of medical complications during inpatient stroke rehabilitation. Chang Gung Medical Journal. 2005; 28: 31-38.

[43] Kalra L, Yu G, Wilson K, Roots P. Medical complications during stroke rehabilitation. Stroke. 1995; 26: 990-994.

[44] Doshi VS, Say JH, Young SH, Doraisamy P. Complications in stroke patients: a study carried out at the rehabilitation medicine service, changi general hospital. Singapore Medical Journal. 2004; 44: 643-652.

[45] Knoflach M, Matosevic B, Rucker M, Furtner M, Mair A, Wille G, et al. Functional recovery after ischemic stroke-a matter of age: data from the Austrian Stroke Unit Registry. Neurology. 2012; 78: 279-285.

[46] Colbert JF, Traystman RJ, Poisson SN, Herson PS, Ginde AA. Sex-related differences in the risk of hospital-acquired sepsis and pneumonia post acute ischemic stroke. Journal of Stroke and Cerebrovascular Diseases. 2016; 25: 2399-2404.

[47] Reeves MJ, Bushnell CD, Howard G, Gargano JW, Duncan PW, Lynch $\mathrm{G}$, et al. Sex differences in stroke: epidemiology, clinical presentation, medical care, and outcomes. The Lancet Neurology. 2008; 7: 915-926.

[48] Sen A. Missing women. British Medical Journal. 1992; 304: 587-588.

[49] Kapoor M, Agrawal D, Ravi S, Roy A, Subramanian SV, Guleria R. Missing female patients: an observational analysis of sex ratio among outpatients in a referral tertiary care public hospital in India. BMJ Open. 2019; 9: e026850.

[50] Balan S, Mahalingam R. Are we losing the war on missing girls? The Lancet Global Health. 2014; 2: e22.

[51] Gupta D. Disparities in development, status of women and social opportunities: Indian experience. Journal of Alternative Perspectives in the Social Sciences. 2009; 1: 687-719.

[52] Grau AJ, Urbanek C, Palm F. Common infections and the risk of stroke. Nature Reviews Neurology. 2010; 6: 681-694.

[53] Davenport RJ, Dennis MS, Wellwood I, Warlow CP. Complications after acute stroke. Stroke. 1996; 27: 415-420.

[54] Weimar C, Roth MP, Zillessen G, Glahn J, Wimmer MLJ, Busse O, et al. Complications following acute ischemic stroke. European Neurology. 2002; 48: 133-140.

[55] Ji R, Wang D, Shen H, Pan Y, Liu G, Wang P, et al. Interrelationship among common medical complications after acute stroke. Stroke. 2013; 44: 3436-3444.

[56] Pandian JD, Kaur A, Jyotsna R, Sylaja PN, Vijaya P, Padma MV, et al. Complications in acute stroke in India (CAST-I): a multicenter study. Journal of Stroke and Cerebrovascular Diseases. 2012; 21: 695-703.

[57] Westendorp WF, Nederkoorn PJ, Vermeij J, Dijkgraaf MG, de Beek DV. Post-stroke infection: a systematic review and meta-analysis. BMC 
Neurology. 2011; 11: 110.

[58] Adams HP, Davis PH, Leira EC, Chang K-, Bendixen BH, Clarke WR, et $a l$. Baseline NIH stroke scale score strongly predicts outcome after stroke: a report of the Trial of Org 10172 in Acute Stroke Treatment (TOAST). Neurology. 1999; 53: 126-131.

[59] Frankel MR, Morgenstern LB, Kwiatkowski T, Lu M, Tilley BC, Broderick JP, et al. Predicting prognosis after stroke: a placebo group analysis from the national institute of neurological disorders and stroke rt-PA stroke trial. Neurology. 2000; 55: 952-959.

[60] Kwakkel G, Kollen BJ. Predicting activities after stroke: what is clinically relevant? International Journal of Stroke. 2013; 8: 25-32.

[61] Haeusler KG, Schmidt WUH, Föhring F, Meisel C, Helms T, Jungehulsing GJ, et al. Cellular immunodepression preceding infectious complications after acute ischemic stroke in humans. Cerebrovascular Diseases. 2008; 25: 50-58.

[62] Sorbello D, Dewey HM, Churilov L, Thrift AG, Collier JM, Donnan G, et al. Very early mobilisation and complications in the first 3 months after stroke: further results from phase II of a very early rehabilitation trial (AVERT). Cerebrovascular Diseases. 2009; 28: 378-383.

[63] Saxena SK, Ng TP, Yong D, Fong NP, Gerald K. Total direct cost, length of hospital stay, institutional discharges and their determinants from rehabilitation settings in stroke patients. Acta Neurologica Scandinavica. 2006; 114: 307-314.

[64] Tong X, Kuklina EV, Gillespie C, George MG. Medical complications among hospitalizations for ischemic stroke in the United States from 1998 to 2007. Stroke. 2010; 41: 980-986.

[65] Kwan J, Hand P. Infection after acute stroke is associated with poor shortterm outcome. Acta Neurologica Scandinavica. 2007; 115: 331-338.

[66] Ovbiagele B, Hills NK, Saver JL, Johnston SC. Frequency and determinants of pneumonia and urinary tract infection during stroke hospitalization. Journal of Stroke and Cerebrovascular Diseases. 2006; 15: 209-213
[67] Badve MS, Zhou Z, van de Beek D, Anderson CS, Hackett ML. Frequency of post-stroke pneumonia: systematic review and metaanalysis of observational studies. International Journal of Stroke. 2019; 14: $125-136$.

[68] Tirschwell DL, Kukull WA, Longstreth WT. Medical complications of ischemic stroke and length of hospital stay: experience in Seattle, Washington. Journal of Stroke and Cerebrovascular Diseases. 1999; 8: 336-343.

[69] Spratt N, Wang Y, Levi C, Ng K, Evans M, Fisher J. A prospective study of predictors of prolonged hospital stay and disability after stroke. Journal of Clinical Neuroscience. 2003; 10: 665-669.

[70] Alvarez-Sabín J, Molina CA, Montaner J, Arenillas JF, Huertas R, Ribo $\mathrm{M}$, et al. Effects of admission hyperglycemia on stroke outcome in reperfused tissue plasminogen activator-treated patients. Stroke. 2003; 34: $1235-1240$.

[71] Chambers BR, Norris JW, Shurvell BL, Hachinski VC. Prognosis of acute stroke. Neurology. 1987; 37: 221-225.

[72] Willmot M, Leonardi-Bee J, Bath PMW. High blood pressure in acute stroke and subsequent outcome. Hypertension. 2004; 43: 18-24.

[73] Pan B, Jin X, Jun L, Qiu S, Zheng Q, Pan M. The relationship between smoking and stroke. Medicine. 2019; 98: e14872.

[74] Modrego PJ, Pina MA, Lerín FJ. The impact of ageing on stroke subtypes, length of stay and mortality: study in the province of Teruel, Spain. Acta Neurol Scand. 2003; 108: 435-442.

How to cite this article: Vishal Madhukar Sawale, Durjoy Lahiri, Ritwik Ghosh, Souvik Dubey, Gautam Das, Goutam Gangopadhyay, et al. Determinants of complications in first ever acute stroke patients: a prospective observational study from India. Signa Vitae. 2021;17(2):145-153. doi:10.22514/sv.2021.002. 